\title{
The probiotic paradox: live and dead cells are biological response modifiers
}

\author{
Clifford A. Adams \\ ANOZENE Nutritional Sciences, Fruithoflaan 103, bus 14, 2600 Berchem, Antwerp, Belgium
}

\begin{abstract}
Probiotics are usually defined as products which contain viable non-pathogenic micro-organisms able to confer health benefits to the host. There are specific gastrointestinal effects of probiotics such as alleviating inflammatory bowel disease, reducing acute diarrhoea in children, inhibiting Salmonella and Helicobacter pylori, removing cholesterol, secreting enzymes and bacteriocins and immunomodulation. However, many of the effects obtained from viable cells of probiotics are also obtained from populations of dead cells. Heat-killed cells of Enterococcus faecalis stimulate the gastrointestinal immune system in chicks. Dead bifidobacteria induce significant increases in TNF- $\alpha$ production. Administration of heat-killed E. faecalis to healthy dogs increases neutrophil phagocytes. The probiotic paradox is that both live and dead cells in probiotic products can generate beneficial biological responses. The action of probiotics could be a dual one. Live probiotic cells influence both the gastrointestinal microflora and the immune response whilst the components of dead cells exert an anti-inflammatory response in the gastrointestinal tract. This is quite analogous to a proposed mode of action of antimicrobial growth promoters in animal production. This has several implications for the production and application of probiotics, as it will be difficult to assess the relative proportions of live and dead cells in a probiotic culture. Variable amounts of dead cells might contribute to the variation in response often seen with live probiotic cultures. However, the use of dead probiotics as biological response modifiers has several attractive advantages; such products would be very safe and have a long shelf-life.
\end{abstract}

Probiotics: Live probiotics: Dead probiotics: Gastrointestinal tract: Immunomodulation

\section{Introduction}

There is a widespread interest nowadays in the health benefits of food components or nutrition-based health ${ }^{(1)}$ and probiotics in particular are potentially an important part of a nutrition-based health strategy. Probiotics are usually defined as dietary supplements, containing viable nonpathogenic micro-organisms, which are considered to confer health benefits to the host ${ }^{(2)}$ through their interactions with the gastrointestinal microflora and directly with the immune system.

The avoidance and reduction of enteric diseases is a major factor in health maintenance, and the microflora of the gastrointestinal tract are well recognised as playing a fundamentally important role here ${ }^{(3)}$. However, interactions between the gastrointestinal microflora and the host are not always beneficial. A disordered recognition of components of the commensal flora by the host seems most probably a major causal effect of inflammatory bowel disease ${ }^{(4,5)}$.
The pathogenesis of Crohn's disease is now widely accepted as a consequence of an aggressive immune response to the continuous antigenic stimulation by gastrointestinal microflora $^{(6,7)}$. Traditional pathogens are probably not responsible for the onset of Crohn's disease but an increased virulence of commensal bacteria interacting with pathogens stimulates the damaging immune response ${ }^{(7)}$.

Therefore, modification of the gastrointestinal microflora by probiotic therapy has therapeutic potential in clinical conditions associated with gastrointestinal barrier dysfunctions and inflamed mucosa. Probiotics may offer a new therapeutic option for the treatment of inflammatory bowel disease as reviewed by Geier et al. ${ }^{(5)}$. Probiotics have been effective in the treatment of acute infectious diarrhoea in children and in the prevention of antibiotic-associated diarrhoea $^{(8-10)}$. There is encouraging evidence for a beneficial effect of probiotics against rotavirus diarrhoea in children ${ }^{(11,12)}$. Probiotics can also be effective in the Abbreviations: EC-12, commercial product of heat-killed Enterococcus faecalis; OVA, ovalbumin; Th1, T helper type 1; Th2, T helper
type 2; VRE, vancomycin-resistant enterococci.

Corresponding author: Clifford Adams, email Cliff.Adams@skynet.be 
prevention and management of pouchitis, paediatric atopic diseases and the prevention of post-operative infections ${ }^{(8)}$. There are many other beneficial properties of probiotics. They can inhibit Salmonella ${ }^{(13-16)}$ and Helicobacter pylori $^{(17)}$, remove cholesterol ${ }^{(18,19)}$, and secrete enzymes ${ }^{(20)}$ and bacteriocins ${ }^{(21)}$ into the gastrointestinal tract.

Future applications of probiotics in human health have been concisely reviewed by Vanderhoof ${ }^{(22)}$. Probiotics might be useful in controlling inflammatory diseases, treating and preventing allergic diseases, preventing cancer and stimulating the immune system, which may reduce the incidence of respiratory disease.

\section{Modes of action of probiotics}

At the cellular level, probiotic micro-organisms have several possible modes of action. They may be able to directly inhibit or kill pathogenic bacteria, and lactobacilli species are often considered to be valuable here ${ }^{(21,23)}$. A second mode of action is that of inhibiting the attachment of pathogens to the wall of the gastrointestinal tract ${ }^{(24)}$. Pathogenic bacteria in the gastrointestinal tract need to attach themselves to the wall of the gut to be able to develop disease syndromes; if probiotic cells can effectively compete with the pathogens for binding sites or bind to the pathogens, the virulence of the pathogens would be reduced. They can have an effect upon host mucosal surfaces, including the mouth, gastrointestinal tract, upper respiratory tract and urogenital tract. Mucosal defence against bacteria is essential for the homeostasis of the host. In the case of the colonised intestine, protection against enteropathogens partly depends upon the indigenous microflora, and probiotics may play a role here.

Probiotics have also been implicated in direct interaction with the immune system as reviewed by Isolauri et al. ${ }^{(25)}$. Many probiotic effects are mediated through immune regulation and through the balance of pro-inflammatory and anti-inflammatory cytokines. The population of intraepithelial $\mathrm{CD}^{+} \mathrm{T}$ cells was significantly enhanced in piglets treated with a probiotic (Bacillus cereus var. Toyoi) ${ }^{(26)}$ and human T-cell proliferation was suppressed by Lactobacillus strains ${ }^{(3)}$. Consumption of Lactobacillus plantarum by healthy humans showed a modulation of $\mathrm{NF}-\kappa \mathrm{B}-$ dependent pathways, which may be related to the establishment of immune tolerance in healthy subjects ${ }^{(27)}$.

There is a wide range of biological responses reported from treatment by various probiotics. These biological responses are also obtained from a diverse range of microbial products. The generally accepted definition of probiotics is that they are live, non-pathogenic microorganisms ingested by the target species which may be human, animal or avian. However, there is considerable published evidence that probiotic preparations comprised of dead cells and their metabolites can also exert a biological response, in many cases similar to that seen with live cells. Consequently, probiotics consisting of either live or dead cells and their metabolites may play an important role in health maintenance and disease avoidance in the host, including modulation of immune responses. This is the crux of the probiotic paradox where both live and dead cells seem to be capable of generating a biological response ${ }^{(28-30)}$.

\section{Some problems with conventional probiotics}

A major problem in the practical application of probiotics and also in the understanding of their mode of action is that heterogeneous effects are often obtained. This may well be due to the differing ability of the probiotic strains to colonise the gastrointestinal tract. Two strains of lactobacilli, L. johnsonii and L. paracasei, have been found to have similar in vitro properties ${ }^{(31)}$. However, when they were administered to germ-free mice they colonised the intestinal lumen and translocated into mucosal lymphoid tissues at different densities. The strain L. johnsonii colonised the intestine very efficiently at high levels whereas the number of $L$. paracasei cells decreased rapidly and it colonised at low levels. Both strains were able to activate B-cell responses but there were clear differences in patterns of immunoglobulins in the mucosa and in the periphery. Therefore, despite similar in vitro properties, distinct lactobacilli strains may colonise the gastrointestinal tract differently and generate divergent biological responses.

Live cells in probiotic products will inevitably lose viability and the actual products will contain varying populations of dead cells ${ }^{(32)}$. The population of dead cells could be even larger than that of live cells but this is frequently not known. This would affect the evaluation of any positive response when the dose was controlled by the number of live cells. In practice it may not be possible to feed only live bacteria to a subject. There will always be the possibility that an unknown amount of dead cells are being administered with the live cells.

Another practical difficulty with probiotics is that ideally they should establish themselves within the gastrointestinal tract and survive in sufficient numbers. However, to do this they need to be of a suitable strain particular to the host animal and this is difficult in practice to achieve, as standardised products must be commercially produced. Furthermore, a probiotic may only achieve a transient colonisation of the gastrointestinal tract. This could arise from a substantial loss of viability of the organisms on passage through the relatively hostile environment of the stomach and small intestine ${ }^{(33,34)}$. The probiotic organisms would have to survive low $\mathrm{pH}$ and proteolytic enzymes. However, many probiotic species such as L. delbrueckii and Streptococcus thermophilus do not readily survive stomach acidity. The recovery of $L$. delbrueckii subsp. bulgaricus from the terminal ileum of minipigs was from 0.04 to $0.5 \%$. Recovery rates of total Strep. thermophilus were 1.2 and $2.2 \%{ }^{(35)}$. Therefore some of the benefits derived from consumption of these probiotics are more likely to accrue from the presence of metabolites or of dead probiotic cells in the gastrointestinal tract ${ }^{(33)}$.

\section{Dead cells as biological response modifiers}

Despite the general definition that probiotics are live microorganisms, a variety of biological responses have been reported from administering dead, frequently heat-killed, probiotics to various mammalian and avian species. The preparations of dead cells have also been fractionated and various cellular components shown to produce a range of biological responses. 


\section{Immunomodulation}

A single administration of heat-killed Enterococcus faecalis FK-23 preparation was evaluated for immune responses in healthy $\operatorname{dog} s^{(36)}$. The probiotic had no effect on the complete blood count or on leucocyte differential count. However, the treatment caused a 1.4-fold increase in neutrophil phagocytic activity compared with non-treated healthy dogs. A single administration of heat-killed probiotic bacteria augmented the host resistance through stimulation of non-specific immune responses in vivo.

There has been considerable further work on heat-killed E. faecalis, which led to the production of a commercial product, EC-12. This is a dried powder of heat-killed cells which has an immunostimulatory function ${ }^{(37)}$. Dietary EC-12 given to newly hatched chicks at $0.05 \%$ of the feed stimulated the gastrointestinal immune system and reinforced the immune reaction against a vancomycinresistant enterococci (VRE) challenge to accelerate its defecation from the chick intestine. As shown in Table 1, the detection frequency (\%) of VRE in cloacal swabs of chicks given EC-12 in the feed was lower on days 3 and 7 compared with the control group and with a group given live chicken Lactobacillus spp. The EC-12 product is produced from dead cells and there was no treatment with live cells of E. faecalis, so no direct comparison between live and dead E. faecalis cells can be made. Nevertheless, the preparation of dead cells was clearly able to generate a biological response.

Total IgA concentration in the caeca digesta was higher in the EC-12 group than in the control group. Total serum IgG concentration also tended to be higher in the EC-12treated chicks than in the other treatments.

This could be a useful treatment technique, as once VRE are established on a farm it is virtually impossible to eliminate them from animal intestines due to their multiple resistance against antimicrobials ${ }^{(38)}$. Therefore there is a real need for alternative strategies to prevent infection or to eliminate colonisation of VRE from the gastrointestinal tract of animals.

In a subsequent study, administration of dead cells of EC-12 to newly hatched broiler chicks stimulated the production of the antimicrobial peptide, $\beta$-defen $\sin ^{(39)}$. This may be one of the major defence mechanisms inhibiting VRE colonisation in young chicks.

Both E. faecalis and Lactobacillus spp. are Gram-positive bacteria and their cell walls are known to stimulate the inflammatory reaction involving macrophages in the mammalian gastrointestinal tract ${ }^{(40-42)}$. They can also

Table 1. Vancomycin-resistant enterococci detection (\%) in cloacal swabs of broiler chicks treated with a conventional live probiotic or with dead probiotic cells of Enterococcus faecalis (EC-12) (Sakai et al. ${ }^{(37)}$ )

\begin{tabular}{lcrrr}
\hline & & \multicolumn{3}{c}{ Age of chicks $(\mathrm{d})$} \\
\cline { 3 - 5 } Treatment & Chicks $(n)$ & \multicolumn{1}{c}{1} & \multicolumn{1}{c}{3} & 7 \\
\hline Control & 13 & 100 & $100^{\mathrm{b}}$ & $77^{\mathrm{a}, \mathrm{b}}$ \\
Lactobacillus (live cells) & 6 & 67 & $100^{\mathrm{b}}$ & $100^{\mathrm{b}}$ \\
EC-12 (dead cells) & 13 & 46 & $31^{\mathrm{a}}$ & $38^{\mathrm{a}}$ \\
\hline
\end{tabular}

a,b Percentages within a column with unlike superscript letters were significantly different $(P<0.05)$. induce B-cell activation and stimulate $\operatorname{Ig} \mathrm{A}$ secretion in the intestine ${ }^{(43)}$. This kind of immunostimulation can lead to a rapid removal of the pathogen from the digestive tract in chicks. The relative rapid decline in VRE detection with the EC-12 treatment (Table 1) suggests the involvement of the innate immune system. As EC-12 is derived from dead cells the protective effect of this material is likely to be an immunostimulation. A possible advantage in using a dead cell preparation is that it cannot acquire and transmit the vancomycin (VCM)-resistant plasmid from VRE. There is clearly substantial evidence that heat-killed preparations of E. faecalis have an immunomodulating effect in both dogs and chicks ${ }^{(36,37,39)}$.

Bifidobacteria are non-pathogenic, Gram-positive organisms that are frequently used in dairy products as a probiotic adjunct. Marin et al. ${ }^{(44)}$ showed that several strains of bifidobacteria had an immunopotentiating activity in clonal murine macrophage and T-cell lines. There was considerable variation in activity among the fourteen different strains of bifidobacteria studied, but four strains used in commercial dairy products were the most stimulatory. This immunomodulation could be elicited by heat-killed bifidobacteria which were able to induce pronounced increases, of up to several hundred-fold, in the production of TNF- $\alpha$ compared with that of controls. IL- 6 production also increased significantly. Upon concurrent stimulation of the macrophages with lipopolysaccharide there was substantial increased production of both TNF- $\alpha$ and IL- 6 when they were cultured with bifidobacteria. It appears that a direct interaction of bifidobacteria with macrophages enhanced cytokine production. Clearly, heat-killed bifidobacteria are able to act as biological response modifiers although the response seen here was pro-inflammatory. Moderate stimulation of pro-inflammatory cytokines could be beneficial in maintaining a good immunological balance and increasing resistance to infections. However, high concentrations of TNF- $\alpha$ are undesirable ${ }^{(44)}$. There is certainly the potential for dead probiotic cells to have adverse effects and careful screening and selection of strains would still be required.

Gastrointestinal epithelial cells secrete a variety of inflammatory cytokines after stimulation by pathogenic bacteria. In particular, IL-6 is produced in response to bacterial infection. This is a multifunctional cytokine involved in diverse biological processes such as the host response to enteric pathogens, acute-phase reactions, haematopoiesis, growth factor for normal or neoplastic cells, and terminal differentiation of B-lymphocytes. This interleukin has traditionally been considered the product of pro-inflammatory cells. However, IL-6 is also known to possess several anti-inflammatory characteristics such as its ability to down-regulate lipopolysaccharide-induced monocyte IL- 1 and TNF- $\alpha$ mRNA expression. Both viable and non-viable probiotic cells were able to stimulate IL-6 production in murine small intestine epithelial cells (Table 2) ${ }^{(43)}$.

The reduction of IL-6 production when intestinal epithelial cells were treated with live bacteria at a dose rate of $1 \times 10^{8}$ cells $/ \mathrm{ml}$ might be due to a diminution in $\mathrm{pH}$ of the culture medium by the metabolically active bacteria. This is consistent with the results for heat-killed bacteria 
Table 2. The effect of viable or heat-killed Lactobacillus casei and L. helveticus on the production of IL- $6(\mathrm{pg} / \mathrm{ml})$ by murine small intestine epithelial cells (Vinderola et al. ${ }^{(43)}$ )

\begin{tabular}{|c|c|c|c|c|}
\hline \multirow[b]{2}{*}{ Treatment } & \multicolumn{4}{|c|}{ Dose of probiotic } \\
\hline & None & $10^{6}$ & $10^{7}$ & $10^{8}$ \\
\hline Negative control & 395 & - & - & - \\
\hline $\begin{array}{l}\text { Positive control } \\
\text { (LPS at } 0.1 \mu \mathrm{g} / \mathrm{ml})\end{array}$ & $890^{*}$ & - & - & - \\
\hline L. casei (viable) & - & $530^{*}$ & $520^{*}$ & $300^{*}$ \\
\hline L. helveticus (viable) & - & $480^{*}$ & $620^{*}$ & $220^{*}$ \\
\hline L. casei (heat-killed) & - & 400 & $500^{*}$ & $620^{*}$ \\
\hline L. helveticus (heat-killed) & - & $580^{*}$ & $650^{*}$ & $720^{*}$ \\
\hline
\end{tabular}

LPS, lipopolysaccharide.

* Significantly different from negative control $(P<0.05)$

where IL-6 production increased as the bacterial load increased (Table 2).

Chuang et al. ${ }^{(45)}$ showed that three heat-killed strains of Lactobacillus were able to modulate immune responses by stimulating proliferation of murine splenocytes. In addition, these heat-killed probiotic cells also stimulated high-level secretion of IL-12 p70 in dendritic cells of mice and they switched $\mathrm{T}$ helper cells to $\mathrm{T}$ helper 1 (Th1) immune responses. Components of lactobacilli cells have the potential to play an important role in modulating immune responses and allergic reactions but this does not depend on the cells being alive.

Both live and heat-killed Lactobacillus GG had an antiinflammatory effect in rats suffering from experimental $\operatorname{arthritis}^{(46)}$. This is similar to the oral treatment with live L. reuteri that significantly attenuated an allergic airway response in mice ${ }^{47)}$. Clearly the anti-inflammatory effect of these probiotics did not depend upon the viability of the micro-organism. In stark contrast to these results, Ma et al. ${ }^{(48)}$ reported that live cultures of $L$. reuteri were essential for an inhibitory effect on expression of IL-8 in human epithelial cell lines. IL- 8 is an important mediator of the innate immune system. The pro-inflammatory cytokine TNF- $\alpha$ induces IL- 8 production and this could only be suppressed by live probiotic cells. Neither heat-killed nor $\gamma$-irradiated cells were able to generate a response. This exemplifies the difficulty of drawing a general consensus on the action of probiotics. In these two studies with L. reuteri different experimental models were used, mice ${ }^{(47)}$ v. an in vitro model with human epithelial cells ${ }^{(48)}$.

There has been a considerable amount of work published on the interactions of probiotics and TNF- $\alpha$ and other cytokines. The probiotic L. rhamnosus GG modulated the TNF- $\alpha$-induced release of IL- 8 from Caco- 2 cells ${ }^{(30)}$. High doses of live L. rhamnosus GG in the absence of TNF- $\alpha$ actually induced the production of IL-8. Heat-killed probiotics also reduced IL- 8 production from TNF- $\alpha$-induced cells. However, by themselves, dead cells caused only a small increase in IL-8 production. This suggests that heat-killed probiotics may be able to prevent intestinal inflammation without the potential pro-inflammatory effect exhibited when the intestinal epithelium is exposed to high quantities of L. rhamnosus GG.

Further work with TNF- $\alpha$ showed that six heat-killed Lactobacillus strains had a pro-inflammatory effect in inducing the secretion of TNF- $\alpha$ from mouse splenic mononuclear cells ${ }^{(49)}$. However, there was a clear difference among strains. The most active L. rhamnosus induced approximately four times more TNF- $\alpha$ than the least active L. casei. It appears that the Lactobacillus strain L. rhamnosus is particularly effective in inducing the production of TNF- $\alpha$. Furthermore, these examples suggest that both live and dead probiotic cells may have an effect outside the gastrointestinal tract, as reviewed by Lenoir-Wijnkoop et al. ${ }^{(50)}$.

A potential problem with live probiotic cells is that they may cause some pathology of their own, particularly in severely immunodeficient patients. However, the use of both heat-killed L. acidophilus and L. casei was able to induce some limited protection against infection with Candida albicans in immunodeficient mice ${ }^{(51)}$. In mice that had been challenged by $C$. albicans, treatment with heat-killed probiotics suppressed orogastric candidiasis 2 weeks after colonisation and also suppressed the number of viable $C$. albicans cells in the gastrointestinal tract. Dead cells of these probiotics did not exacerbate any problems and were able to offer some limited protection against candidiasis in immunodeficient mice.

\section{Colitis}

Experimental colitis as a disease model can be induced in Wistar rats by treatment with indomethacin ${ }^{(52)}$. Treatment with a proprietary probiotic administered either orally or subcutaneously had an anti-inflammatory effect and prevented gastrointestinal lesions. The response was obtained with both live and dead probiotic cells. Supplying dextran sodium sulfate in the drinking water can also induce experimental colitis in mice and this is another useful model to study the effect of probiotics ${ }^{(53,54)}$. The severity of this experimental colitis was attenuated by either non-viable $\gamma$-irradiated, or by viable probiotics, but not by heat-killed probiotics in this instance (Table 3$)^{(53)}$. The probiotics used here were a commercial preparation containing four strains of lactobacilli, three strains of bifidobacteria and one strain of Strep. salivarius subsp. thermophilus.

Further investigations showed that the experimental colitis was ameliorated by the administration of probiotic DNA $^{(53)}$. However, methylated probiotic DNA, calf thymus DNA, and DNAase-treated probiotics had no effect. These results suggest that the protective effects of probiotics in this instance were mainly mediated by their own DNA rather than by their metabolites or their ability to colonise the colon. Heat treatment may have denatured the DNA so that heat-killed cells were no longer active.

Table 3. Effect of viable and dead probiotics on experimental colitis in mice induced by treatment with dextran sodium sulfate (Rachmilewitz et al. ${ }^{(53)}$ )

Treatment Disease activity score

None (control) 8.0

Viable probiotics

Irradiated probiotics

Heat-killed probiotics

$7 \cdot 0$ 
Oral administration of Bacillus polyfermenticus by oral administration protected mouse colonic mucosa from inflammatory responses due to colitis induced either by dextran sodium sulfate or by 2,4,6 trinitrobenzenesulfonic $\operatorname{acid}^{(54)}$. The biological responses seen here both with live and dead cells are a result of the probiotic interacting with the gastrointestinal mucosa rather than with the microflora. It is molecular components of the probiotic that generate the biological response and this could probably be achieved with either live or dead cells. The most likely mode of action is through stimulation of Toll-like receptors which exert an immunomodulatory effect in the gastrointestinal tract ${ }^{(53,54)}$.

\section{Modulation of pain response}

Live, heat-killed or $\gamma$-irradiated $L$. reuteri or medium containing metabolites from the bacteria were orally administered to rats suffering visceral pain induced by colorectal distension $^{(55)}$. The probiotic treatment inhibited the pain response to colorectal distension through effects on enteric nerves. This is another example where dead probiotic cells seem to have an effect outside the gastrointestinal tract.

\section{Allergic diseases}

Allergic diseases such as atopic dermatitis, atopic eczema and allergic rhinitis are serious social problems in many countries $^{(29)}$. These allergic diseases are characterised by an elevation in serum IgE levels ${ }^{(56)}$, which in turn is generally thought to be caused by a skewed balance between Th1 and Thelper type 2 (Th2) cells ${ }^{(57)}$. The balance of the two types of cells is considered to be important to maintain homeostasis of the host. L. casei strain Shirota was killed by heating and lyophilised before being used to treat mice that had been injected intraperitoneally with ovalbumin (OVA) to induce IgE production ${ }^{(57)}$. Treatment with the heat-killed Lactobacillus reduced total $\mathrm{IgE}$ production in mouse serum. This suggests that administration of heatkilled cells of $L$. casei strain Shirota could be a treatment against allergic diseases.

A total of fifty-nine strains of heat-killed $L$. brevis were examined for their ability to induce IL-12 and interferon- $\gamma$ from mouse Peyer's patches cells ${ }^{(58)}$. Strains which were selected for their ability to induce a strong Th1 immune response inhibited both total $\operatorname{IgE}$ and antigen-specific $\operatorname{IgE}$ production and improved the Th1/Th2 balance by enhancing IL-12 and interferon- $\gamma$ and inhibiting IL-4 production from OVA-sensitised mouse splenocytes.

These in vitro results were followed by animal trials using mice ${ }^{(58)}$. A particular strain of L. brevis, SBC8803, was fed to OVA-sensitised mice at $0.5 \%$ of the diet for 4 weeks. Total and OVA-specific IgE in the serum of mice which were fed the heat-killed bacterium was significantly lower than that of the control mice. The interferon- $\gamma / \mathrm{IL}-4$ value, which represents the Th1/Th2 balance, from splenocytes from the mice fed the L. brevis was significantly higher than that seen in the splenocytes from the control mice not fed the $L$. brevis. The results shown here for L. casei Shirota ${ }^{(57)}$ and L. brevis ${ }^{(58)}$ were probably due to the heat-killed probiotics improving the Th1/Th2 balance in favour of a predominance of Th1 cells.

In a subsequent study, twenty strains of heat-killed lactobacilli isolated from human subjects were screened for their stimulatory activity to produce cytokines by murine splenocytes in vitro and by their ability to suppress $\operatorname{IgE}$ production when they were orally administered to allergic mice ${ }^{(29)}$. One strain of $L$. gasseri had a higher stimulatory activity of the cytokine IL-12 production than the other lactobacilli tested. Oral administration of $L$. gasseri was more effective in reducing the serum antigen-specific $\operatorname{IgE}$ levels in OVA-sensitised mice compared with other lactobacilli and the control (Table 4). Furthermore, the stimulatory activity for IL-12 production was reduced after treating the lactobacilli with $N$-acetyl-muramidase and tended to be positively correlated with the amount of peptidoglycan in the cells.

Several different reports indicate that heat-killed lactobacilli strains - L. casei strain Shirota ${ }^{(57)}$, . . brevis $^{(58)}$ and $L$. gasserij ${ }^{(29)}$ - can improve the Th1/Th2 balance and inhibit IgE production. Clearly, dead probiotic cells can act as biological response modifiers for allergic diseases.

\section{Reduction of cholesterol}

Another effect of probiotics is that of reducing cholesterol. Eleven strains of lactobacilli were able to remove between 31 and $97 \%$ of cholesterol from the medium, so this phenomenon may be a general effect of probiotics ${ }^{(18)}$. Again, both live and heat-killed cells were able to remove cholesterol. Cholesterol removed by dead or resting cells ranged from 0.79 to $3.82 \mathrm{mg} / \mathrm{g}$ of dry weight compared with growing cells, which ranged from 4.53 to $16.03 \mathrm{mg} / \mathrm{g}$ of dry weight. Heat-killed cells of lactococci and of lactobaccilli were also able to take up cholesterol although at a lower rate than living cells. This is probably due to binding to the cell surface ${ }^{(18,19)}$. Strains of lactococci and of lactobaccilli probably remove cholesterol by two mechanisms. One is through assimilation of cholesterol by living cells and two is by binding to the cell walls. Adhesion to the cell surface could occur in both living and dead cells and therefore dead cells may be promising candidates as a dietary supplement to lower serum cholesterol.

Table 4. Effect of oral administration of heat-killed lactic acid bacteria on serum IgE level in ovalbumin-sensitised mice as a model for allergic disease (Sashihara et al. ${ }^{(29)}$ )

\begin{tabular}{lc}
\hline Lactobacilli strain & $\begin{array}{c}\text { Serum IgE } \\
\text { (arbitrary units/ml) }\end{array}$ \\
\hline None (control) & 1850 \\
Lactobacillus crispatus JCM 1185T & 1500 \\
L. plantarum JCM 1149T & 1600 \\
L. plantarum JCM MEP 170402 & 2200 \\
L. gasseri JCM 1131 ${ }^{3} \mathrm{~T}$ & 950 \\
L. gasseri MEP 170407 & 960 \\
L. gasseri MEP 170413 & 1010 \\
L. gasseri OLL 2809 & $800^{\star}$ \\
\hline
\end{tabular}

* Significantly different from control $(P<0.05)$. 
Table 5. The effect of dietary $\beta$-glucans on the concentrations of various cytokines induced by lipopolysaccharides (LPS) in the plasma of pigs (Li et al. ${ }^{(67)}$ )

(Mean values with their pooled standard errors)

\begin{tabular}{|c|c|c|c|c|c|c|}
\hline \multirow[b]{2}{*}{ Cytokine } & \multirow[b]{2}{*}{ Time (h) } & \multicolumn{2}{|r|}{$\beta$-Glucans at $0 \mathrm{ppm}$} & \multicolumn{2}{|c|}{$\beta$-Glucans at $50 \mathrm{ppm}$} & \multirow[b]{2}{*}{ SEM } \\
\hline & & No LPS & LPS at $25 \mu \mathrm{g} / \mathrm{kg}$ body weight & No LPS & LPS at $25 \mu \mathrm{g} / \mathrm{kg}$ body weight & \\
\hline \multirow[t]{2}{*}{ IL-6 (pg/ml) } & 0 & 149 & 148 & 135 & 149 & 8.9 \\
\hline & 3 & 164 & 415 & 142 & 349 & $25 \cdot 6$ \\
\hline \multirow[t]{2}{*}{ TNF- $\alpha(n g / m l)$} & 0 & 0.61 & 0.55 & 0.50 & 0.45 & 0.04 \\
\hline & 3 & 0.53 & 5.94 & 0.48 & 4.67 & 0.53 \\
\hline \multirow[t]{2}{*}{$\mathrm{IL}-10(\mathrm{pg} / \mathrm{ml})$} & 0 & 85 & 84 & 92 & 97 & 4.43 \\
\hline & 3 & 89 & 105 & 105 & 127 & 5.06 \\
\hline
\end{tabular}

ppm, Parts per million.

\section{Activities of probiotic cell fractions}

There is considerable evidence that not only dead cells, but also metabolites and cell fractions of probiotics can exert a biological response. Various microbiological components such as cell homogenates ${ }^{(59,60)}, \beta$-glucans ${ }^{(61)}$, teichoic and lipoteichoic acids ${ }^{(49)}$, peptidoglycans, lipopolysaccharides and DNA ${ }^{(53,62)}$ have an immunomodulating effect, probably through stimulating the innate immune system.

Heat-treated homogenates were prepared from various probiotic bacteria; L. rhamnosus GG, Bifidobacterium lactis, L. acidophilus, L. delbrueckii subsp. bulgaricus and Strep. thermophilus ${ }^{(59)}$. All the homogenates suppressed phytohaemagglutinin-induced proliferation of human blood peripheral mononuclear cells. When the proliferation assays were repeated with cytoplasmic and cell-wall extracts derived from the homogenate of L. rhamnosus GG, the cytoplasmic extract, but not the cell-wall extract, was suppressive $^{(59)}$. These bacteria possess a heat-stable antiproliferative component that is not associated with the cell wall.

Probiotic-mediated biological responses have also been demonstrated in fish cells. Two teleost fish cell lines SAF-1, a fibroblast cell line, and epithelioma papulosum cyprini (EPC), an epithelioma from carp, were used ${ }^{(60)}$. These cells rapidly proliferate and biological responses were assayed as an anti-proliferative effect and the induction of apoptosis. The cells were grown in the presence of cytoplasmic extracts from two probiotic strains of $L$. delbrüeckii subsp. lactis ${ }^{(60)}$. The SAF-1 cells were more susceptible to growth inhibition by the probiotic extracts than were the EPC cells.
Apoptosis took place following growth inhibition, which indicated that cytoplasmic extracts of probiotic bacteria were able to exert an immunological response in cultured fish cells.

These studies ${ }^{(59,60)}$ are a good model for the responses of commensal and pathogenic bacteria in the gastrointestinal tract. Generally, bacteria and bacterial homogenates of the commensal gastrointestinal microflora do not stimulate proliferation of mononuclear cells ${ }^{(63)}$ and this plays an important role in the maintenance of hyporesponsiveness to foreign antigens ${ }^{(64)}$. Pathogens, in contrast, stimulate the proliferation of mucosal immune cells and this produces an inflammatory reaction ${ }^{(63,65)}$. Cell contents from probiotic bacteria suppress immune responses in vitro in human blood mononuclear cells and in cells from fish, suggesting that this may be a widespread response. This has interesting possibilities for the further development of probiotic-based products. Non-viable cell extracts would probably have a long shelf-life and be easier to store in commercial practice.

Both crude extracts and purified lipoteichoic acids from L. case $i$ and L. fermentum could significantly induce TNF- $\alpha$ secretion from mouse splenic mononuclear cells ${ }^{(49)}$. This suggests that purified lipotechoic acids may be a better candidate for clinical use than whole bacteria since they do not contain other bacterial components which might cause side effects.

In mice with experimentally induced colitis, DNA from a commercial probiotic mixture ameliorated the severity of the disease. Methylated probiotic DNA, calf thymus DNA and DNase-treated probiotics had no effect ${ }^{(53)}$.

Table 6. Biological responses to dead cells of various probiotics

Biological response

Ameliorate arthritis

Anti-inflammatory effect

Attenuate colitis

Attenuate visceral pain

Cholesterol binding

Pro-inflammatory effect, inducing TNF- $\alpha$ secretion

Reduce allergic diseases through reduction of IgE

Reduce IL-8 production from TNF- $\alpha$-induced cells

Stimulate gastrointestinal immune system against VRE

Stimulate IL-6 production

Stimulate proliferation of splenocytes

Suppress mononuclear cell proliferation

Systemic effects

\section{References}

Baharav et al. (2004) ${ }^{(46)}$

Zhang et al. (2005) ${ }^{(30)}$, Chuang et al. (2007) $)^{(45)}$

Laudanno et al. (2006)(52), Rachmilewitz et al. $(2004)^{(53)}$, Im et al. $(2009)^{(54)}$

Kamiya et al. (2006) ${ }^{(55)}$

Kimoto et al. (2002) ${ }^{(18)}$, Liong \& Shah (2005) $)^{(19)}$

Marin et al. (1997) ${ }^{(44)}$, Matsuguchi et al. $(2003)^{(49)}$, Lenoir-Wijnkoop et al. (2007) ${ }^{(50)}$

Sashihara et al. (2006) ${ }^{(29)}$, Matsuzaki et al. (1998) $)^{(57)}$, Segawa et al. (2008)

Zhang et al. (2005)

Sakai et al. (2006) $)^{(37)}$, Sakai et al. (2007) ${ }^{(39)}$

Marin et al. (1997) ${ }^{(44)}$

Chuang et al. (2007) ${ }^{(45)}$

Pessi et al. (1999) ${ }^{(59)}$, Salinas et al. $(2008)^{(60)}$

Wagner et al. $(2000)^{(51)}$, Kamiya et al. (2006) ${ }^{(55)}$

VRE, vancomycin-resistant enterococci. 
Oral treatment of mice with probiotic DNA resulted in a reduction in mucosal secretion of $\mathrm{TNF}-\alpha$ and an improvement in histological disease ${ }^{(62)}$. It is interesting here to note that the probiotic DNA was effective when given orally. The possibility of oral dosing is a big advantage for the practical application of probiotics. In these examples also the protective effects of the probiotics were mediated by their DNA rather than by an ability to colonise the gastrointestinal tract.

Extracellular polysaccharides from L. delbrueckii ssp. bulgaricus OLL1073R-1 were able to generate an immunomodulatory response ${ }^{(66)}$. Fractionation of these polysaccharides yielded an active high-molecular-weight acidic phosphopolysaccharide containing D-glucose and D-galactose. Stimulation of mouse splenocytes by this acidic polysaccharide significantly increased interferon- $\gamma$ production. Oral administration of the phosphopolysaccharide to mice augmented natural killer cell activity. Production of the active phosphopolysaccharide was strain specific in that L. bulgaricus OLL1256 and Strep. thermophilus OLS3059 did not have an immunomodulating effect.

The $\beta$-glucans in particular have been referred to as biological response modifiers ${ }^{(61)}$, but this term can be applied to many different components of microbial origin. Such responses clearly have nothing to do with live or viable probiotic preparations. $\beta$-Glucans extracted from the cell walls of Saccharomyces cerevisiae are able to potentiate the immune system. A dose rate of 50 parts per million (ppm) was able to improve the growth rate of pigs ${ }^{(67)}$. The mode of action may be related to immune responses, as the $\beta$-glucans at $50 \mathrm{ppm}$ partially suppressed increases in plasma concentration of IL- 6 and TNF- $\alpha$ brought about by a lipopolysaccharide challenge (Table 5). There was an increase in IL-6 up to $415 \mathrm{ng} / \mathrm{ml}$ without $\beta$-glucans, but only $349 \mathrm{ng} / \mathrm{ml}$ with $\beta$-glucans. Similarly, the increase in TNF- $\alpha$ was reduced from 5.94 to $4.67 \mathrm{ng} / \mathrm{ml}$. Conversely, $\beta$-glucans enhanced the increase in plasma concentrations of IL-10.

The cytokines IL- 6 and TNF- $\alpha$ are pro-inflammatory and they not only modulate immunity but can also directly regulate nutrient metabolism and cause detrimental effects upon animal performance. IL-10 is an anti-inflammatory cytokine that suppresses the activity of the transduction of NF- $\mathrm{NB}$, which is a major transcription factor of proinflammatory cytokines. Therefore, if feeding $\beta$-glucans promotes secretion of anti-inflammatory cytokines such as

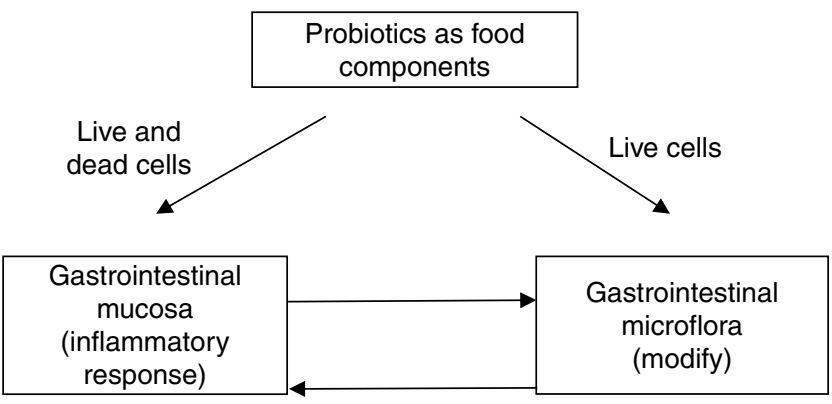

Fig. 1. Proposed dual function of probiotics where live and dead cells interact with the gastrointestinal mucosa and live cells also interact with the gastrointestinal microflora.
IL-10 and decreases secretion of pro-inflammatory cytokines such as TNF- $\alpha$ and IL-6, then less activation of the immune system would be achieved, which could result in improved growth performance.

\section{Conclusions}

It is clear that both live and dead cells in probiotic products can generate a wide range of biological responses ${ }^{(8)}$. The specific biological responses generated by dead probiotic cells are summarised in Table 6. These responses have been obtained from in vitro cell-culture studies and from in vivo studies with mice, rats, dogs and chickens.

Many of the biological responses found with both live and dead probiotics are not antimicrobial effects but are, rather, immunomodulating effects. Frequently they seem to exert an anti-inflammatory effect upon the cells of the gastrointestinal tract. This is quite analogous to the proposed mode of action of antimicrobial growth promoters in animal production ${ }^{(68)}$.

Antimicrobial growth promoters have for many years proved to be effective in improving growth and feed efficiency in species such as pigs and poultry. These antimicrobial growth promoters are in fact antibiotics added to the feed of animals in low sub-therapeutic amounts. Despite their widespread use over many years the precise mode of action of antimicrobial growth promoters has never been conclusively elucidated.

It seems, however, that an antibiotic mechanism for the mode of action of antimicrobial growth promoters is unlikely and that their target is not the microflora in the gastrointestinal tract. Most antibiotics also have a nonantibiotic, anti-inflammatory effect upon the cells of the gastrointestinal tract. They attenuate the inflammatory response. Consequently, the levels of pro-inflammatory cytokines would be lower than those in untreated animals.

The effect of probiotics could thus be a dual one where live probiotic cells might well influence the gastrointestinal microflora and have an immunomodulating effect, whereas the components of dead cells could exert an anti-inflammatory response (Fig. 1). However, the relative importance of these two effects is difficult to assess since an immunomodulating response of both live and dead probiotic cells has been extensively investigated. Dead probiotic cells are not a necessary requirement to generate a biological response but they may be sufficient.

Therefore the positive effects shown by both live and dead probiotic preparations illustrate the probiotic paradox. The findings that live probiotics may not be mandatory to be beneficial could have a major impact on the practical use and manufacturing of probiotics ${ }^{(28)}$. It will be difficult to assess the proportion of dead cells in a viable probiotic culture. Consequently, variable amounts of dead cells might well contribute to the variation in response often seen with live probiotic cultures. Conversely, it is relatively easy to demonstrate that cultures of killed probiotic products would not contain any live cells. Products based on dead cells would be relatively easy to standardise and would have a long shelf-life. Also the use of dead cells would permit a wider range of micro-organisms to be considered as probiotics. Clearly with live cultures, only well-recognised 
non-pathogenic species can be used. Products based on dead cells could be produced from many species of microorganisms.

The use of dead probiotics as biological response modifiers has several other attractive advantages. There is always the risk that live probiotic bacteria could cause some pathology of their own. Severely immunodeficient subjects may be at risk from treatment with live probiotics and therefore the use of dead cells would be a safer alternative. It is likely that dead cells would not suffer from the low $\mathrm{pH}$ conditions in the stomach. It may also be possible to produce microbiologically non-viable yet immunologically active probiotic food products that are easier to store and have a long shelf-life.

The biological response-modifying activity of dead probiotic cells is clearly somewhat similar to an oral immunisation response from a vaccine. In calves use of a live vaccine based on Salmonella typhimurium gave excellent protection against a challenge infection by a virulent strain of S. typhimurium ${ }^{(69)}$. Oral immunisation of mice with a vaccine based on killed $S$. typhimurium was also quite effective ${ }^{(70)}$. A vaccine prepared from formalin-killed cells of enterotoxigenic Escherichia coli cells induced a strong immune response in human subjects ${ }^{(71)}$. Similarly, an oral dose of inactivated whole-cell Pseudomonas aeruginosa vaccine given to human volunteers had no adverse safety implications ${ }^{(72)}$. There was also a significant increase in intracellular macrophage killing of opsonised $P$. aeruginosa in the presence of the post-vaccination sera.

There is substantial evidence from in vitro studies and animal studies that both live and dead probiotic cells can act as biological response modifiers. These observations suggest that a food supplement based on dead probiotic cells could represent an intermediate stage between an oral vaccine and a classical live probiotic. Such a product could have applications both in animal husbandry and in human health.

\section{Acknowledgements}

There are no conflicts of interest. The present review received no specific grant from any funding agency in the public, commercial or not-for-profit sectors.

\section{References}

1. Adams CA (2007) Nutrition-based Health: Nutricines and Nutrients, Health Maintenance and Disease Avoidance in Animals. Nottingham: Nottingham University Press.

2. Food and Agriculture Organization \& World Health Organization (2001) Health and Nutritional Properties of Probiotics in Food Including Powder Milk with Live Lactic Acid Bacteria. Report of a Joint FAO/WHO Expert Consultation on Evaluation of Health and Nutritional Properties of Probiotics in Food Including Powder Milk with Live Lactic Acid Bacteria. Rome: FAO.

3. Peluso H, Fina D, Caruso R, et al. (2007) Lactobacillus paracasei subsp. paracasei B21060 suppresses human T-cell proliferation. Infect Immun 75, 1730-1737.

4. Guarner F (2005) The intestinal flora in inflammatory bowel disease: normal or abnormal. Curr Opin Gastroenterol 2 , 414-418.
5. Geier MS, Butler RN \& Howarth GS (2007) Inflammatory bowel disease: current insights into pathogenesis and new therapeutic options; probiotics, prebiotics and synbiotics. Int J Food Microbiol 115, 1-11.

6. Sellon RK, Tonkonogy S, Schultz M, et al. (1998) Resident enteric bacteria are necessary for development of spontaneous colitis and immune system activation in interleukin10-deficient mice. Infect Immun 66, 5224-5231.

7. Sartor RB (2008) Microbial influences in inflammatory bowel diseases. Gastroenterology 134, 577-594.

8. Gill H \& Guarner F (2004) Probiotics and human health: a clinical perspective. Postgrad Med J 80, 516-526.

9. Rosenfeldt V, Michaelsen KF, Jakobsen M, et al. (2002) Effect of probiotic Lactobacillus strains in young children hospitalized with acute diarrhea. Pediatr Infect Dis $J$ 21, 411-416.

10. Canani RB, Cirillo P, Terrin G, et al. (2007) Probiotics for treatment of acute diarrhoea in children: randomised clinical trial of five different preparations. BMJ 335, 340-345.

11. Fang S-B, Lee H-C, Hu J-J, et al. (2009) Dose-dependent effect of Lactobacillus rhamnosus on quantitative reduction of faecal rotavirus shedding in children. J Trop Pediatr 55, 297-301.

12. Pant N, Marcotte H, Brussow H, et al. (2007) Effective prophylaxis against rotavirus diarrhea using a combination of Lactobacillus rhamnosus GG and antibodies. BMC Microbiol 7, 86 .

13. Higgins JP, Higgins SE, Vicente JL, et al. (2007) Temporal effects of lactic acid bacteria probiotic culture on Salmonella in neonatal broilers. Poultry Sci 86, 1662-1666.

14. Higgins SE, Erf GF, Higgins JP, et al. (2007) Effect of probiotic treatment in broiler chicks on intestinal macrophage numbers and phagocytosis of Salmonella enteritidis by abdominal exudate cells. Poultry Sci 86, 2315-2321.

15. Valdez JC, Rachid M, Gobbato N, et al. (2001) Lactic acid bacteria induce apoptosis inhibition in Salmonella typhimurium infected macrophages. Food Agric Immunol 13, 189-197.

16. Higgins JP, Higgins SE, Wolfenden AD, et al. (2010) Effect of lactic acid bacteria probiotic culture treatment timing on Salmonella enteritidis in neonatal broilers. Poult Sci 89, 243-247.

17. Sgouras D, Maragkoudakis P, Petrak K, et al. (2004) In vitro and in vivo inhibition of Helicobacter pylori by Lactobacillus casei strain Shirota. Appl Environ Microbiol 70, 518-526.

18. Kimoto H, Ohmomo S \& Okamoto T (2002) Cholesterol removal from media by lactococci. J Dairy Sci $\mathbf{8 5}$, 3182-3188.

19. Liong MT \& Shah NP (2005) Acid and bile tolerance and cholesterol removal ability of Lactobacillus strains. J Dairy Sci 88, 55-66.

20. Yu B, Liu JR, Hsiao FS, et al. (2008) Evaluation of Lactobacillus reuteri $\mathrm{Pg} 4$ strain expressing heterologous $\beta$-glucanase as a probiotic in poultry diets. Anim Feed Sci Technol 141, 82-91.

21. Svetoch EA, Eruslanov BV, Pereglyn VV, et al. (2008) Diverse antimicrobial killing by Enterococcus faecium E 50-52 bacteriocin. J Agric Food Chem 56, 1942-1948.

22. Vanderhoof JA (2001) Probiotics: future directions. Am J Clin Nutr 73, Suppl., 1152S-1155S.

23. Siggers RH, Siggers J, Boye M, et al. (2008) Early administration of probiotics alters bacterial colonization and limits diet-induced gut dysfunction and severity of necrotizing enterocolitis in preterm pigs. J Nutr 138, 1437-1444.

24. Candela M, Perna F, Carneval P, et al. (2008) Interaction of probiotic Lactobacillus and Bifidobacterium strains with 
human intestinal epithelial cells: adhesion properties, competition against enteropathogens and modulation of IL-8 production. Int J Food Microbiol 125, 286-292.

25. Isolauri E, Sütas Y, Kankaanpää P, et al. (2001) Probiotics: effects on immunity. Am J Clin Nutr 73, Suppl., 444S-450S.

26. Scharek L, Altherr BJ, Tölke C, et al. (2007) Influence of the probiotic Bacillus cereus var. Toyoi on the intestinal immunity of piglets. Vet Immunol Immunopathol 120, 136-147.

27. Van Baarlen P, Troost FJ, van Hemert S, et al. (2009) Differential NF-кB pathways induction by Lactobacillus plantarum in the duodenum of healthy humans correlating with immune tolerance. Proc Nat Acad Sci U S A 106, 2371-2376.

28. Dotan I \& Rachmilewitz D (2005) Probiotics in inflammatory bowel disease: possible mechanisms of action. Curr Opin Gastroenterol 21, 426-430.

29. Sashihara T, Sueki N \& Ikegami S (2006) An analysis of the effectiveness of heat-killed lactic acid bacteria in alleviating allergic diseases. J Dairy Sci 89, 2846-2855.

30. Zhang L, Nan L, Caicedo R, et al. (2005) Alive and dead Lactobacillus rhamnosus GG decrease tumor necrosis factor- $\alpha$-induced interleukin- 8 production in Caco- 2 cells. J Nutr 135, 1752-1756.

31. Ibnou-Zekri N, Blum S, Schiffrin EJ, et al. (2003) Divergent patterns of colonization and immune response elicited from two intestinal Lactobacillus strains that display similar properties in vitro. Infect Immun 71, 428-436.

32. Nighswonger BD, Brashears MM \& Gilliland SE (1996) Viability of Lactobacillus acidophilus and Lactobacillus casei in fermented milk products during refrigerated storage. J Dairy Sci 79, 212-219.

33. Maldonado Galdeano C \& Peridgón G (2004) Role of viability of probiotic strains in their persistence in the gut and in mucosal immune stimulation. J Appl Microbiol 97, 673-681.

34. Conway PL, Gorbach SL \& Goldin BR (1987) Survival of lactic acid bacteria in the human stomach and adhesion to intestinal cells. J Dairy Sci 70, 1-12.

35. Lick S, Drescher K \& Heller JK (2001) Survival of Lactobacillus delbrueckii subsp. bulgaricus and Streptococcus thermophilus in the terminal ileum of fistulated Göttingen minipigs. Appl Environ Microbiol 67, 4137-4143.

36. Kanasugi H, Hasegawa T, Goto Y, et al. (1997) Single administration of enterococcal preparation (FK-23) augments non-specific immune responses in healthy dogs. Int $J$ Immunopharmacol 19, 655-659.

37. Sakai Y, Tsukahara T, Bukawa W, et al. (2006) Cell preparation of Enterococcus faecalis strain EC-12 prevents vancomycin-resistant enterococci colonization in the cecum of newly hatched chicks. Poultry Sci 85, 273-277.

38. Sørum M, Johnsen PJ, Aasnes B, et al. (2006) Prevalence, persistence, and molecular characterization of glycopeptideresistant enterococci in Norwegian poultry and poultry farmers 3 to 8 years after the ban on Avoparcin. Appl Environ Microbiol 72, 516-521.

39. Sakai Y, Tsukahara T, Matsubara N, et al. (2007) A cell wall preparation of Enterococcus faecalis strain EC-12 stimulates $\beta$-defensin expression in newly hatched chicks. Anim Sci J 78, 92-97.

40. Hatcher GE \& Lambrecht RS (1993) Augmentation of macrophage phagocytic activity by cell-free extracts of selected lactic acid-producing bacteria. J Dairy Sci 76, 2485-2492.

41. Baken KA, Ezendam J, Gremmer ER, et al. (2006) Evaluation of immunomodulation by Lactobacillus casei
Shirota: immune function, autoimmunity and gene expression. Int J Food Microbiol 112, 8-18.

42. Benyacoub J, Pérez PF, Rochat F, et al. (2005) Enterococcus faecium SF68 enhances the immune response to Giardia intestinalis in mice. J Nutr 135, 1171-1176.

43. Vinderola G, Matar C \& Perdigon G (2005) Role of intestinal epithelial cells in immune effects mediated by Gram-positive probiotic bacteria: involvement of Toll-like receptors. Clin Diagn Lab Immunol 12, 1075-1084.

44. Marin ML, Lee JH, Ustunol MZ, et al. (1997) Differential cytokine production in clonal macrophage and T-cell lines cultured with bifidobacteria. J Dairy Sci 80, 2713-2720.

45. Chuang L, Keh-Gong W, Pal C, et al. (2007) Heat-killed cells of lactobacilli skew the immune response toward $\mathrm{T}$ helper 1 polarization in mouse splenocytes and dendritic cell-treated T cells. J Agric Food Chem 55, 11080-11086.

46. Baharav E, Mor F, Halpern M, et al. (2004) Lactobacillus GG bacteria ameliorate arthritis in Lewis rats. J Nutr 134, 1964-1969.

47. Forsythe P, Inman MD \& Bienenstock J (2007) Oral treatment with live Lactobacillus reuteri inhibits the allergic airway response in mice. Am J Resp Critical Care Med 175, $561-569$.

48. Ma D, Forsythe P \& Bienenstock J (2004) Live Lactobacillus reuteri is essential for the inhibitory effect on tumor necrosis factor $\alpha$-induced intereukin-8 expression. Infect Immun 72, 5308-5314.

49. Matsuguchi T, Takagi A, Matsuzaki T, et al. (2003) Lipoteichoic acids from Lactobacillus strains elicit strong tumor necrosis factor $\alpha$-inducing activities in macrophages through Toll-like receptor 2. Clin Diagn Lab Immunol 10, 259-266.

50. Lenoir-Wijnkoop I, Sanders ME, Cabana MD, et al. (2007) Probiotic and prebiotic influence beyond the intestinal tract. Nutr Rev 65, 469-489.

51. Wagner RD, Pierson C, Warner T, et al. (2000) Probiotic effects of feeding heat-killed Lactobacillus acidophilus and Lactobacillus casei to Candida albicans-colonized immunodeficient mice. J Food Prot 63, 638-644.

52. Laudanno O, Vasconcelos L, Catalana J, et al. (2006) Anti-inflammatory effect of bioflora probiotic administered orally or subcutaneously with live or dead bacteria. Dig Dis Sci 51, 2180-2183.

53. Rachmilewitz D, Katakura K, Karmeli F, et al. (2004) Tolllike receptor 9 signaling mediates the anti-inflammatory effects of probiotics in murine experimental colitis. Gastroenterology 126, 520-528.

54. Im E, Choi YJ, Pothoulakis C, et al. (2009) Bacillus polyfermenticus ameliorates colonic inflammation by promoting cytoprotective effects in colitic mice. J Nutr 139, 1848-1854.

55. Kamiya T, Wang L, Forsythe P, et al. (2006) Inhibitory effects of Lactobacillus reuteri on visceral pain induced by colorectal distension in Sprague-Dawley rats. Gut 55, 191-196.

56. Hopkin JM (2002) The rise of atopy and links to infection. Allergy 57, Suppl. 72, 5-9.

57. Matsuzaki T, Yamazaki R, Hashimoto S, et al. (1998) The effect of oral feeding of Lactobacillus casei strain Shirota on immunoglobulin E production in mice. J Dairy Sci 81, 48-53.

58. Segawa S, Nakakita Y, Takata Y, et al. (2008) Effect of oral administration of heat-killed Lactobacillus brevis SBC8803 on total and ovalbumin-specific immunoglobulin E production through the improvement of Th1/Th2 balance. Int J Food Microbiol 121, 1-10. 
59. Pessi T, Sütas Y, Saxelin M, et al. (1999) Antiproliferative effects of homogenates derived from five strains of candidate probiotic bacteria. Appl Environ Microbiol 65, 4725-4728.

60. Salinas I, Meseguer J \& Esteban Á (2008) Antiproliferative effects and apoptosis induction by probiotic cytoplasmic extracts in fish cell lines. Vet Microbiol 126, 287-294.

61. Miura NN, Ohno N, Aketagawa J, et al. (1996) Blood clearance of $(1 \rightarrow 3)-\beta$-D-glucan in MRL lpr/lpr mice. FEMS Immunol Med Microbiol 13, 51-57.

62. Jijon H, Backer J, Diaz H, et al. (2004) DNA from probiotic bacteria modulates murine and human epithelial and immune function. Gastroenterology 126, 1358-1373.

63. Duchmann R, Kaiser I, Hermann E, et al. (1995) Tolerance exists towards resident intestinal flora but is broken in active inflammatory bowel disease (IBD). Clin Exp Immunol 102, 448-455.

64. Moreau MC \& Corthier G (1988) Effect of the gastrointestinal microflora on induction and maintenance of oral tolerance to ovalbumin in $\mathrm{C} 3 \mathrm{H} / \mathrm{HeJ}$ mice. Infect Immun 56, 2766-2768.

65. Jiang Y, Magli L \& Russo M (1999) Bacterium-dependent induction of cytokines in mononuclear cells and their pathologic consequences in vivo. Infect Immun 67, 2125-2130.

66. Makino S, Ikegami S, Kano H, et al. (2006) Immunomodulatory effects of polysaccharides produced by Lactobacillus delbrueckii ssp. bulgaricus OLL1073R-1. J Dairy Sci 89, $2873-2881$

67. Li J, Li F, Xing JJ, et al. (2006) Effects of $\beta$-glucan extracted from Saccharomyces cerevisiea on growth performance, and immunological and somatotropic responses of pigs challenged with Escherichia coli lipopolysaccharide. J Anim Sci 84, 2374-2381.

68. Niewold TA (2007) The nonantibiotic anti-inflammatory effect of antimicrobial growth promoters, the real mode of action? A hypothesis. Poultry Sci 86, 605-609.

69. Lindberg AA \& Robertsson JA (1983) Salmonella typhimurium infection in calves: cell-mediated and humoral immune reactions before and after challenge with live virulent bacteria in calves given live or inactivated vaccines. Infect Immun 41, $751-757$

70. Waldman RH, Grunspan R \& Ganguly R (1972) Oral immunization of mice with killed Salmonella typhimurium vaccine. Infect Immun 6, 58-61.

71. Wenneras C, Svennerholm A-M, Ahren C, et al. (1992) Antibody-secreting cells in human peripheral blood after oral immunization with an inactivated enterotoxigenic Escherichia coli vaccine. Infect Immun 60, 2605-2611.

72. Cripps AW, Peek K, Dunkley M, et al. (2006) Safety and immunogenicity of an oral inactivated whole-cell Pseudomonas aeruginosa vaccine administered to healthy human subjects. Infect Immun 74, 968-974. 